https://doi.org/10.29296/25877305-2018-09-20

\section{Обоснование применения}

\section{гепатопротекторов при псориазе}

\author{
Е. Денисова ${ }^{1,2}$, кандидат медицинских наук, \\ Е. Дворянкова ${ }^{2}$, доктор медицинских наук, \\ М. Дениева ${ }^{3}$, кандидат медицинских наук, \\ В. Соболев ${ }^{2}$, \\ И. Корсунская ${ }^{1,2}$, доктор медицинских наук, профрессор \\ ${ }^{1}$ Московский научно-практический центр дерматовенерологии \\ и косметологии \\ ${ }^{2}$ Центр теоретических проблем фризико-химической \\ фармакологии, Москва \\ зРеспубликанский кожно-венерологический диспансер, \\ Грозный \\ E-mail: marykor@bk.ru
}

Современные исследования свидетельствуют о коморбидности псориаза и различных нарушений гепатобилиарной системы. Чаще всего встречается сочетание псориаза и неалкогольной жировой болезни печени. В работе описаны общие звенья патогенеза данных заболеваний, что является одной из причин включения в комплексную терапию псориаза гепатопротективных средств. Собственное исследование демонстрирует преимущества препарата, содержащего эссенциальные фосфолипиды и глицирризированную кислоту, перед традиционной терапией гепатопротекторами.

Ключевые слова: псориаз, патологии гепатобилиарной системы, эссенциальные фосфолипиды, глицирризиновая кислота.

Для цитирования: Денисова Е., Дворянкова Е., Дениева М. и др. Обоснование применения гепатопротекторов при псориазе // Врач. - 2018; 29 (9): 85-88. https://doi.org/10.29296/25877305-2018-09-20

$\mathrm{H}$ а сегодняшний день псориаз является важной медицинской и социально-экономической проблемой. По результатам эпидемиологических исследований в России частота псориаза среди взрослого населения составляет 1-3\% [1]. Кроме неуклонного роста заболеваемости данный дерматоз характеризуется рефрактерным течением, трудностями в достижении стойкой ремиссии и высоким уровнем коморбидности с другими патологиями $[2,3]$.

Современная медицина уделяет большое внимание изучению состояния гепатобилиарной системы при псориазе. При гистологическом исследовании 503 биоптатов печени больных псориазом в $24,0 \%$ случаев обнаружено ее жировое перерождение, в $1,4 \%$ - неспецифическое перипортальное воспаление и у $1 \%$ пациентов - портальный фиброз, что связывают как непосредственно с течением основного заболевания, так и с побочными эффектами цитостатиков [4, 5]. Кроме того у пациентов, страдающих псориазом, наблюдается нарушения белковосинтетической и дезинтоксикаци- онной функций печени, изменение равновесия желчных кислот и повышение активности фосфолипазы А2 в сыворотке крови [6, 7].

Из-за частых случаев диагностирования метаболического синдрома у пациентов с псориазом высокая распространенность неалкогольной жировой болезни печени (НАЖБП) в этой группе не вызывает удивления. Имеющиеся данные свидетельствуют о том, что риск НАЖБП у больных псориазом примерно в 2 раза выше, чем в общей популяции (48-59\%) [8]. Важно отметить, что развитие НАЖБП у пациентов с псориазом, по-видимому, происходит независимо от приема потенциально гепатотоксичных антипсориатических препаратов, таких как метотрексат и анти-TNF-агенты [9]. Результаты нескольких исследований показывают, что сочетание псориаза и НАЖБП может усугубить течение обеих патологий и способствовать развитию фиброза печени [8].

Существует этиопатогенетическая связь между псориазом и НАЖБП. Некоторые провоспалительные цитокины, синтезированные лимфоцитами и кератиноцитами в коже больных псориазом, включая IL6, IL17 и TNF $\alpha$, могут способствовать системной резистентности к инсулину, что является общим патогенетическим звеном этих патологий [8]. Другой важный фактор представляет воспаление висцеральной жировой ткани, которое усугубляет как псориатический процесс, так и повреждение печени из-за повышенной секреции различных факторов, таких как неэтерифицированные жирные кислоты, гормоны и провоспалительные адипокины (TNF $\alpha$, IL6, висфатин, лептин и резистин), а также из-за снижения продукции адипонектина [10]. Хотя эта связь еще не подтверждена экспериментально, существует мнение, что усиленное выделение неэтерифицированных жирных кислот может способствовать развитию и псориаза [11]. С другой стороны, НАЖБП, особенно ее тяжелые формы, способны усугублять инсулинорезистентность, способствуя развитию дислипидемии, увеличению синтеза провоспалительных, прокоагулянтных, прооксидантных и профибогенных медиаторов (CRP, IL6, фибриноген, ингибитор активатора плазминогена-1 и фактор роста опухоли- $\beta$ ) в печени. Все эти процессы могут быть вовлечены в патогенез псориаза, стимулируя пролиферацию кератиноцитов и воспаление кожи [11].

В свою очередь, многие системные антипсориатические препараты, особенно метотрексат, способны вызывать ятрогенное повреждение гепатоцитов, стеатоз печени и фиброз [12]. Все изложенное свидетельствует о необходимости включения в комплексную терапию псориаза гепатопротективных средств. Традиционно в качестве гепатопротектора назначается препарат, содержащий эссенциальные фосфолипиды (ЭФ). Однако препараты, содержащие ЭФ и глицирризиновую кислоту, оказывают влияние на звенья патогенеза не 
только гепатобилиарных нарушений, но и псориаза, что может повысить эффективность терапии и комплаентность пациентов лечению [13].

\section{МАТЕРИАЛ И МЕТОДЫ}

Под нашим наблюдением находилось 89 пациентов (13 женщин и 76 мужчин) в возрасте от 22 до 73 лет с диагнозом распространенный псориаз; средняя длительности заболевания составила $13,6 \pm 12,8$ года. Только у 17 пациентов сопутствующие заболевания в анамнезе отсутствовали. В остальных случаях имели место различные сочетания патологии гепатобилиарной системы, сердечно-сосудистых заболеваний, метаболических нарушений (сахарный диабет, дислипидемия), венерических заболеваний и т.д. Со стороны гепатобилиарной системы были зарегистрированы следующие заболевания: гепатит $\mathrm{C}(\mathrm{n}=5)$, жировой гепатоз $(\mathrm{n}=8)$ и хронический холецистит $(\mathrm{n}=7)$, у остальных пациентов с изменениями биохимических показателей крови $(\mathrm{n}=23)$ сопутствующий диагноз не установлен.

Bсе пациенты были разделены на 2 группы, сопоставимые по гендерному, возрастному составу и распространенности сопутствующих заболеваний.

В 1-ю группу были включены 39 пациентов 34 (87,2\%) мужчин, $5(12,8 \%)$ женщины; средний возраст - 43,5 11,9 года; средняя продолжительность анамнеза заболевания - 14,5 66,5 года. Сопутствующие заболевания гепатобилиарной системы включали: гепатит $\mathrm{C}(\mathrm{n}=4)$, жировой гепатоз $(\mathrm{n}=1)$, гепатомегалия $(\mathrm{n}=1)$, хронический холецистит $(\mathrm{n}=3)$.

Пациентам была назначена комплексная терапия, включавшая гепатопротектор Фосфоглив. Препарат назначался по ступенчатой схеме: лиофилизат 5 г/сут однократно внутривенно струйно в течение 10 дней с последующим переходом на пероральный прием по 2 капсулы 3 раза в сутки до 8 нед. Парентеральную терапию Фосфогливом получили все 39 участников. Полный курс завершили 29 больных - 10 пациентов выбыли из исследования из-за отказа наблюдаться после выписки из стационара.

В составе основной терапии пациенты получали препараты с гепатотоксическим потенциалом - метотрексат $(\mathrm{n}=21)$, УФБ-терапию $(\mathrm{n}=10)$, ПУВА-терапию с аммифурином $(\mathrm{n}=8)$.

Во 2-ю группу были включены 40 пациентов $32(80,0 \%)$ мужчины и $8(20,0 \%)$ женщин. Средний воз-

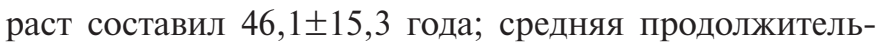
ность анамнеза заболевания - 13,6 $\pm 12,8$ года. У 7 пациентов был диагностирован хронический холецистит, у 5 - жировой гепатоз, у 1 - гепатит С, у 1 - алкогольная болезнь печени, у 1 - цирроз печени.

Больным назначена комплексная терапия, включающая гепатопротектор Эссенциале. В течение первых 10 дней Эссенциале Н вводился по 5 г/сут однократно внутривенно струйно. Затем пациенты переводились на Эссенциале Форте Н по 2 капсулы 3 раза в сутки до 8 нед.

Полный курс завершили 33 пациента -7 больных выбыли из исследования из-за отказа наблюдаться после выписки из стационара.

В составе основной терапии пациенты 2-й группы, как и 1-й, получали препараты с гепатоксическим потенциалом - метотрексат ( $\mathrm{n}=22)$, УФБ-терапию $(\mathrm{n}=12)$, ПУВА-терапию с аммифурином $(\mathrm{n}=6)$.

\section{РЕЗУЛЬТАТЫ И ОБСУЖДЕНИЕ}

Результаты биохимического анализа крови 29 пациентов 1-й группы, завершивших полный курс препарата Фосфоглив, проведенного до начала лечения, выявили следующие отклонения: повышение активности аланинаминотрансферазы (АЛТ) и аспартатаминотрансферазы (АСТ) отмечалось у $27,6 \%$; активности гамма-глутамилтранспептидазы (ГГТП) и щелочной фосфатазы (ЩФ) - соответственно у 55,1 и $51,7 \%$; уровни креатинина и общего билирубина превышали нормальные значения у $34,5 \%$. В 72,4\% случаев имел место повышенный уровень общего холестерина.

Результаты биохимического анализа крови пациентов 2-й группы, проведенного до начала терапии, показали повышение уровня АЛТ и общего билирубина у $24,2 \%$ пациентов, у $1 / 3$ больных наблюдался повышенный уровень содержания АСТ, ГГТ и холестерина в крови, более чем у $50 \%$ - повышенный уровень ЩФ, а у $21,2 \%$ пациентов уровень креатинина в крови превышал значения нормы.

Динамика биохимических показателей крови. На 11-й день терапии после завершения парентерального курса гепатопротектора у больных группы Фосфоглива отмечалось статистически значимое снижение активно-

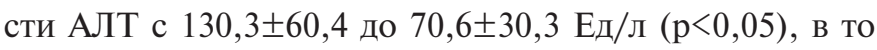
время как в группе Эссенциале за этот же временно́й интервал динамика показателя была недостоверной с 75,6 $\pm 20,7$ до 74,8 $\pm 20,1$ Ед/л. Динамка значений активности АСТ, ГГТ, ЩФ также была более выраженной в группе Фосфоглива. При этом статистически значимая разница $(\mathrm{p}<0,05)$ между группами наблюдается только при сравнении снижения активности

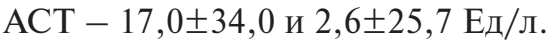

На 56-й день терапии (полный курс) в группе Фосфоглива отмечалось статистически значимое снижение $(\mathrm{p}<0,05)$ значений всех биохимических показателей, по сравнению с исходными уровнями. Активность АЛТ

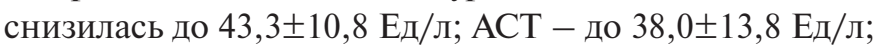

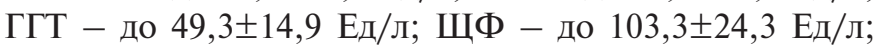
уровень общего билирубина - до 19,0土4,5 мкмоль/л. В группе Эссенциале достоверно $(\mathrm{p}<0,05)$ снизились только активность АЛТ до $45,9 \pm 18,1$ Ед/л и ЩФ до $155,4 \pm 31,2$ Ед/л.

Несмотря на проводимую терапию с гепатотоксическим потенциалом, повышения уровня креатинина 


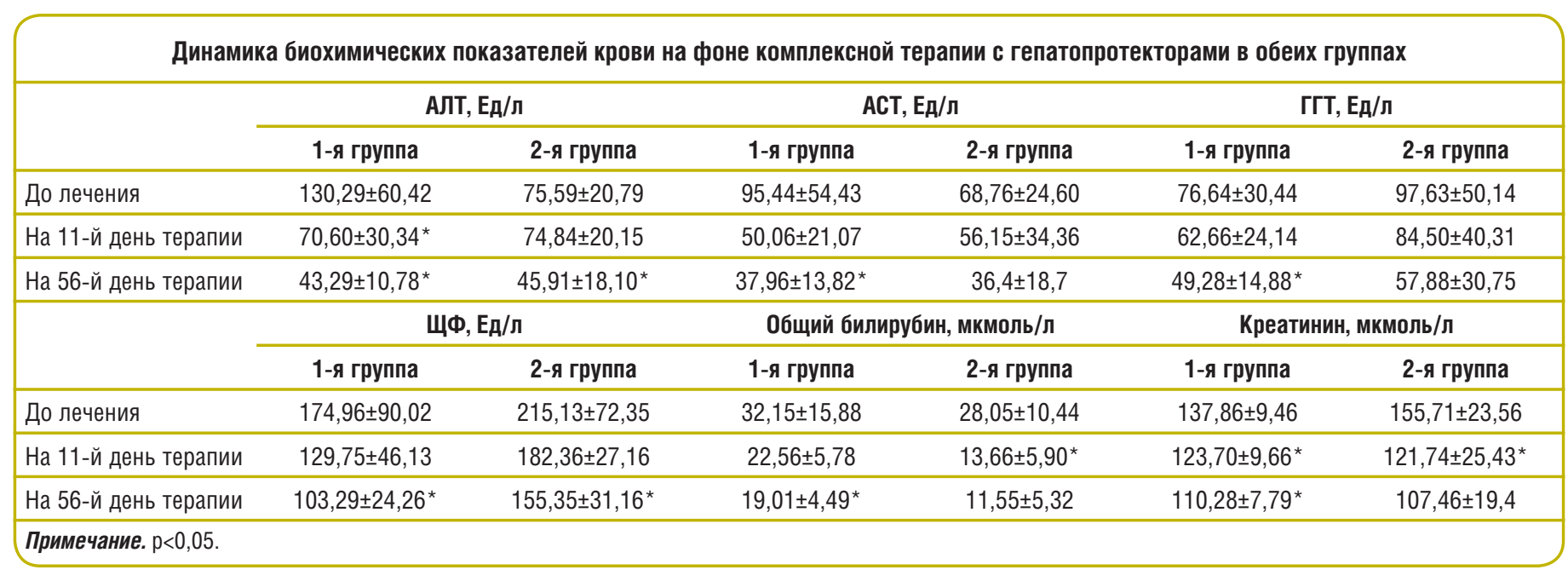

не наблюдалось ни в одной из групп. При исходно нормальных значениях биохимических показателей крови их отрицательная динамика отсутствовала.

Необходимо отметить снижение уровня общего холестерина крови в обеих группах, что может быть связано с нормализацией функций печени.

Динамика биохимических показателей крови в группах представлена в таблице.

Динамика псориатического процесса. Клинически значимые различия между группами были зафиксированы при оценке динамики псориатического процесса. В группе Фосфоглива отмечался интенсивный регресс высыпаний - уменьшение шелушения и инфильтрации. К 20-му дню высыпания полностью разрешились, оставив пигментные пятна. Наблюдение в течение 8 нед терапии показало отсутствие свежих высыпаний.

В группе Эссенциале Н также наблюдался регресс кожных проявлений псориаза, но значительно менее выраженный. Полного разрешения всех высыпаний к 20-му дню терапии достичь не удалось.

Данная динамика была подтверждена расчетом индекса PASI. До назначения терапии средние значения показателя в 1-й и 2-й группах были сопоставимыми - соответственно $31,2 \pm 4,7$ и $32,7 \pm 4,2$ балла, что соответствует псориазу тяжелого течения. После назначенного комплексного лечения статистически значимая положительная динамика наблюдалась в обеих группах. Через 11 дней терапии среднее значение индекса в группе Фосфоглива оказалось достоверно ниже, чем в группе Эссенциале $\mathrm{H}-16,90 \pm 4,02$ против $24,8 \pm 4,4$ балла $(\mathrm{p}<0,05)$. Статистическая значимость различий между группами сохранилась и через 56 дней терапии $-2,7 \pm 1,3$ против $8,2 \pm 5,6$ балла $(\mathrm{p}<0,05)$; см. рисунок.

Безопасность. Применяемая в обеих группах комплексная терапия, включающая гепатопротективные препараты, не вызвала каких-либо нежелательных эффектов, что говорит о безопасности применения Фосфоглива и Эссенциале Н при лечении псориаза.
Данные литературы, результаты исследований и накопленный практический опыт не позволяют сомневаться в наличии этиопатогенетической связи псориаза и заболеваний гепатобилиарной системы. Высокая распространенность этих патологических состояний в популяции наряду с их взаимоотягчающим влиянием заставляют рассматривать данную коморбидность как мультидисциплинарную проблему.

Врачам терапевтического профиля - терапевтам, врачам общей практики, гастроэнтерологам не следует пренебрегать оценкой состояния кожных покровов пациентов, особенно с заболеваниями гепатобилиарной системы. При подозрении на псориаз необходимо своевременное направление к дерматологу. Назначенное дерматологом лечение должно учитываться и контролироваться в рамках комплексного наблюдения пациента. Особого внимания у таких пациентов заслуживает состояние функции печени и коррекция его отклонений с использованием эффективных и безопасных препаратов.

Врачам-дерматологам следует тщательно контролировать состояние печени на фоне антипсориатического

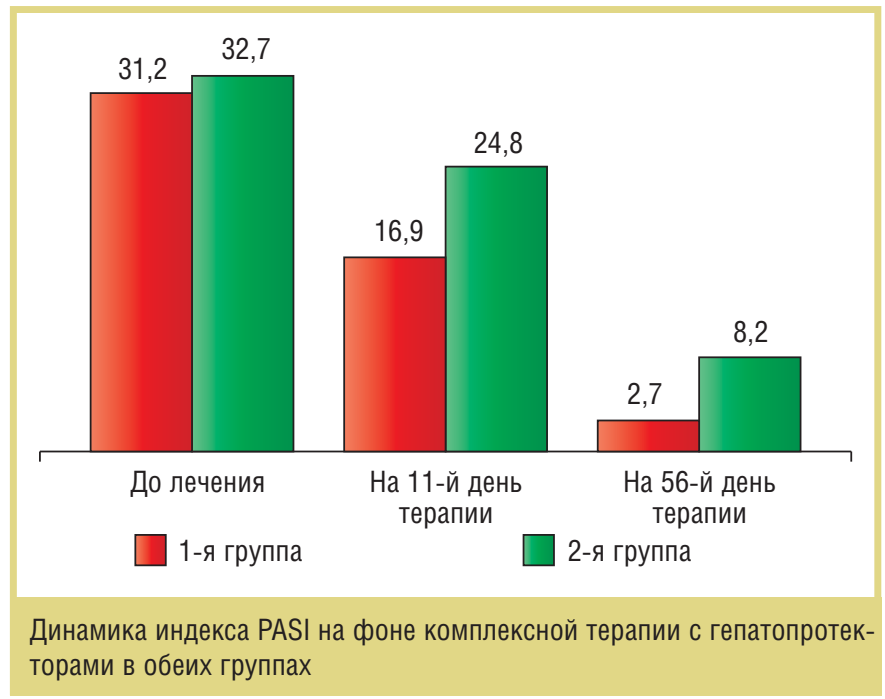


лечения. Терапевтический протокол должен быть соответствующим образом изменен всякий раз, когда появляются какие-либо признаки нарушения функции печени. При назначении препаратов с известным гепатотоксическим потенциалом и (или) развитии гепатотоксических реакций в ходе лечения следует решать вопрос о назначении гепатопроекторов с привлечением при необходимости к принятию решения врача терапевтического профиля.

Проведенное исследование показало, что комбинация эссенциальных фосфолипидов с глицирризиновой кислотой по сравнению с монотерапией эссенциальными фосфолипидами позволяет быстрее нормализовать биохимические показатели функции печени, оказывая на них в целом более выраженное влияние. Кроме того, наличие глицирризиновой кислоты обеспечивает дополнительное терапевтическое действие на псориатический процесс, обеспечивая его более быстрый и существенный регресс. Последнее, вероятно, связано с наличием у нее псевдокортикостероидного эффекта. Профиль безопасности комбинированного препарата можно характеризовать как благоприятный.

Таким образом, псориаз и заболевания гепатобилиарной системы являются коморбидными, а терапия подобных сочетанных состояний требует мультидисциплинарного подхода. Включение в комплексную терапию комбинации эссенциальных фосфолипидов и глицирризиновой кислоты позволяет решить две задачи - обеспечить гепатопротекцию и оптимизировать основное лечение без ухудшения профиля безопасности и увеличения лекарственной нагрузки на пациента. Это свидетельствует о рациональности подобного выбора в реальной клинической практике.

$$
* * *
$$

Конфликт интересов авторами не заявлен.

\section{Литература}

1. Олисова 0.Ю. Псориаз: эпидемиология, патогенез, клиника, лечение // Дерматология. - 2010; 4: 3-8.

2. Саутин М. Е., Соболева А.Г., Золотаренко А.Д. и др. Экспрессия МMP-2 и ММР-9 при псориазе и атеросклерозе // Рос. журн. кожн. и венерич. болезней. $-2013 ; 1$ : $27-9$
3. Галиева Н.В., Головатенко-Абрамов П.К., Нестерова А.П. и др. Биоинформационный анализ молекулярно-генетических процессов при псориазе и болезни Крона // Соврем. проблемы дерматовенерол., иммунол. и врачебной косметол. - 2012; 3: 12-9.

4. Kalb R., Strober B., Weinstein G. et al. Methotrexate and psoriasis: 2009 National Psoriasis Foundation Consensus Conference // J. Am. Acaddermatol. 2009; 60 (5): 824-37.

5. Lindsay K., Fraser A., Layton A. et al. Liver fibrosis in patients with psoriasis and psoriatic arthritis on long-term, high cumulative dose methotrexate therapy // Rheumatology (Oxford). - 2009; 48 (5): 569-72.

6. Загритдинова Р.М., Филимонов М.А., Трусов В.В. и др. Функциональные нарушения гепатобилиарной системы у больных псориазом и возможности их коррекции // Вестн. дерматол. и венерол. - 2006; 3: 11-4.

7. Яковенко Г.Т., Корсунская И.М., Кривощапов Л.Г. Адеметионин в комплексной терапии псориаза // Клин. дерматол. и венерол. - 2013; 6: 59-62.

8. Pietrzak D., Pietrzak A., Krasowska D. et al. Digestive system in psoriasis: an update // Arch. Dermatol. Res. - 2017; 309 (9): 679-93. D0I: 10.1007/s00403-0171775-7.

9. Gisondi P., Targher G., Zoppini G. et al. Non-alcoholic fatty liver disease in patients with chronic plaques psoriasis // J. Hepatol. - 2009; 51: 758-64. D0I: 10.1016/j.jhep.2009.04.020.

10. Loria P., Carulli L., Bertolotti M. et al. Endocrine and liver interaction: the role of endocrine pathways in NASH // Nat. Rev Gastroenterol. Hepatol. - 2009; 6 (4): 236-47.

11. Mantovani A., Gisondi P., Lonardo A. et al. Relationship between NonAlcoholic Fatty Liver Disease and Psoriasis: A Novel Hepato-Dermal Axis? // Int. J. Mol. Sci. - 2016; 17 (2): 217

12. Hardwick R., Clarke J., Lake A. et al. Increased susceptibility to methotrexateinduced toxicity in nonalcoholic steatohepatitis // Toxicol. Sci. - 2014; 142 (1): 45-55

13. Денисова Е.В., Дворянкова Е.В., Плиева К.Т. и др. Патологии гепатобилиарной системы у больных псориазом // Эффективная фрармакотерапия. Дерматология и косметология. - 2018; 1: 26-30.

\section{RATIONALE FOR THE USE OF HEPATOPROTECTIVE AGENTS IN THE TREATMENT OF PSORIASIS}

E. Denisova ${ }^{1,2}$, Candidate of Medical Sciences; E. Dvoryankova ${ }^{2}, M D ;$ M. Denieva $^{3}$ Candidate of Medical Sciences3; V. Sobolev2; Professor I. Korsunskaya ${ }^{1,2}$, MD

${ }^{1} M o s c o w$ Research-and-Practical Center for Dermatovenereology and Cosmetology

${ }^{2}$ Center for Theoretical Problems of Physicochemical Pharmacology, Moscow

${ }^{3}$ Republican Dermatovenereology Dispensary, Groznyi

Current studies indicate comorbidity of psoriasis and various hepatobiliary disorders Concurrence of psoriasis and non-alcoholic fatty liver disease is most frequently encountered. The paper describes common components in the pathogenesis of these diseases, which is one of the reasons for incorporating hepatoprotective agents in the combination therapy of psoriasis. The authors' investigation demonstrates the advantage of a drug containing essential phospholipids and glycyrrhizic acid over conventional therapy with hepatoprotective drugs. Key words: psoriasis, hepatobiliary diseases, essential phospholipids, glycyrrhizic acid

For citation: Denisova E., Dvoryankova E., Denieva M. et al. Rationale for the use of hepatoprotective agents in the treatment of psoriasis // Vrach. - 2018; 29 (9): 85-88. https://doi.org/10.29296/25877305-2018-09-20 